\title{
Inhibition of the High Affinity Myo-Inositol Transport System: A Common Mechanism of Action of Antibipolar Drugs?
}

\author{
Beate Lubrich, Ph.D., and Dietrich van Calker, M.D., Ph.D.
}

The mechanism of action of antibipolar drugs like lithium, carbamazepine, and valproate that are used in the treatment of manic-depressive illness, is unknown. Lithium is believed to act through uncompetitive inhibition of inositolmonophosphatase, which results in a depletion of neural cells of inositol and a concomitant modulation of phosphoinositol signaling. Here, we show that lithium ions, carbamazepine, and valproate, but not the tricyclic antidepressant amitriptyline, inhibit at therapeutically relevant concentrations and with a time course similar to their clinical actions the high affinity myo-inositol transport in astrocyte-like cells and downregulate the level of the respective mRNA. Inhibition of inositol uptake could thus represent an additional pathway for inositol depletion, which might be relevant in the mechanism of action of all three antibipolar drugs. [Neuropsychopharmacology 21:519-529, 1999] (C) 1999 American College of Neuropsychopharmacology. Published by Elsevier Science Inc.

\section{KEY WORDS: Affective disorders; Mood stabilizer; SMIT}

Manic-depressive disorder is an at least in part genetically transmitted illness that affects one to two percent of the population and is characterized by episodic mood swings in the form of depressive, and manic episodes (Goodwin and Jamison 1990). It can be effectively treated acutely and prophylactically by antibipolar drugs like lithium salts, carbamazepine and valproate. Recent evidence indicates that lithium's beneficial effects might be related to a modulation of cellular signal transducing mechanisms (for review see Berridge et al. 1989; Jope and Williams 1994). In particular, the "inositol depletion" hypothesis (Berridge et al. 1989) conjectures that

From the Department of Psychiatry, University of Freiburg, Freiburg, Germany.

Address correspondence to: Dietrich van Calker, Ph.D., M.D., Department of Psychiatry, University of Freiburg, Hauptstraße 5, D79104 Freiburg, Germany.

Received November 3, 1998; revised March 4, 1999; accepted March 17, 1999. lithium might act via depletion of susceptible brain areas of myo-inositol, which is necessary to form inositolphospholipids, an integral part of the cell membrane. The breakdown of these lipids by receptor-triggered activation of phospholipase $\mathrm{C}$ leads to the formation of the two second messenger molecules, inositol-1,4,5-trisphosphate and diacylglycerol (DAG), which regulate many cellular activities. The lithium induced decrease of the cellular inositol content is postulated to selectively impair pathological overactivation of this system via insufficient supply of inositol for the resynthesis of inositolphospholipid or perhaps other mechanisms secondary to inositol depletion such as activation of protein kinase C (PKC) by accumulated DAG (Jope and Williams 1994). The reason for lithium's inositol depleting effect and for its selectivity for overactivated neural circuits is believed to be the inhibition of inositolmonophosphatase (IMPase), which is of the uncompetitive type and therefore the more pronounced the more substrate (inositolmonophosphate, IMP) is formed by breakdown of inositolphospholipids. The inositol depletion hypothesis rests 
on the assumption that brain cells almost completely rely on inositol formed from IMP, either as a final product of the hydrolysis of inositolphospholipids or as an intermediate of the de-novo-synthesis of inositol from glucose-6-phosphate. However, recent evidence indicates that brain cells may also accumulate inositol from the extracellular space to a variable degree, which might stipulate the cellular sensitivity to the inositol depleting effect of lithium (for review see Gani et al. 1993). Indeed, the myo-inositol content shows remarkable differences in different areas of the rat brain already at basal conditions and is altered by treatment with high concentrations of myo-inositol with kinetics that are distinct in each area (Patishi et al. 1996). Furthermore, the inositol depletion induced by lithium salts is, after chronic treatment, restricted to the hypothalamus (Lubrich et al. 1997). One potential source of the region-specific differences in inositol content and uptake is the high affinity myo-inositol transport system, which has been characterized in various cell types including those of neural origin (Wiesinger 1991). This system is inhibited by activation of PKC (Handler and Kwon 1993; Batty et al. 1993). Since lithium via increased accumulation of DAG can activate and later downregulate PKC (for review Manji and Lenox 1994; Manji et al. 1995), we hypothesized that the activity of the high affinity inositol uptake might also be influenced by lithium. Here, we report that not only lithium, but also the other antibipolar drugs carbamazepine and valproate, decrease both the activity of the high affinity inositol transporter and the levels of its mRNA in cultured astrocyte-like cells. These effects may be of relevance for the mechanism of action of these drugs, since the effects are seen at therapeutically relevant concentrations and develop with a time course similar to that of the clinical actions.

\section{METHODS}

When not mentioned otherwise, chemicals were purchased from Merck (Darmstadt, Germany). Carbamazepine, lithium, and valproate containing media was obtained by addition of the required amount of the respective substance (all purchased from Sigma, Munich,

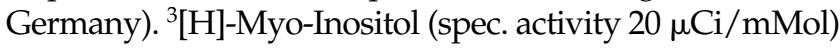
was from Amersham, Braunschweig, Germany. Drugs were dissolved in growth medium with the exception of carbamazepine which was prepared as a stock solution in DMSO (final concentration of DMSO in the medium $0.1 \%$; DMSO at this concentration did not influence the uptake of ${ }^{3}[\mathrm{H}]$-myo-Inositol).

\section{Primary Astrocytes}

Astrocyte cultures were established as described previously (Gebicke-Haerter et al. 1989). In brief, rat brains were dissected out of newborn Wistar rat pups (<1day). Various regions (cerebellum, cortex, diencephalon, hippocampus, and tegmentum) were isolated. Brain tissues were gently dissociated by trituration in Dulbecco's phosphate buffered saline (PBS) (GIBCO BRL, Eggenstein) and filtered through cell strainer (70 $\mu \mathrm{m}$ Ø; Falcon, Meylan, France) into Dulbecco's modified Eagles Medium (DMEM). After two washing steps cells were seeded into 24-well-dishes (Falcon) $\left(5 \times 10^{5}\right.$ cells/well) or 6-well-dishes (Falcon) $\left(2 \times 10^{6}\right.$ cells/well) for uptake experiments or RNA extraction respectively. Cultures were maintained for four weeks in DMEM containing 10\% fetal calf serum with $0.01 \%$ penicillin and $0.01 \%$ streptomycin in a humidified atmosphere $\left(5 \% \mathrm{CO}_{2}\right)$ at $37^{\circ} \mathrm{C}$. Culture medium was changed on the second day after preparation and twice weekly thereafter. These cultures contain over $95 \%$ astrocyte-like cells as determined immunocytochemically and are therefore generally referred to as "cultured astrocytes", although strictly speaking they are rather "astroglia-rich cultures." They contain, in addition, microglia and some minor contamination of other cell types such as ependymal cells but no neurons (for review see Hamprecht and Löffler 1985).

\section{Human Astrocytoma Cell Line U373 MG}

The human astrocytoma cell line U373 MG (initial stock kindly provided by Dr. Bernd Fiebich, Dept. of Psychiatry, University of Freiburg, Germany) was grown in minimal essential medium-Earle's medium (MEM; Seromed, Berlin, Germany) containing 10\% fetal calf serum, L-glutamine, antibiotics, vitamins, amino acids, and pyruvate. For the uptake experiment cells were plated on 24 well dishes ( $10^{5}$ cells/well).

\section{Uptake Experiments}

For determination of ${ }^{3}[\mathrm{H}]$ myo-inositol accumulation, cultures were washed twice with PBS and incubated up to 24 hours with culture medium containing $42 \mu \mathrm{M}$ (primary astrocytes) or $13 \mu \mathrm{M}$ (astrocytoma cells) myoinositol $(40 \mu \mathrm{M}$ or $11 \mu \mathrm{M}$ myo-inositol respectively are present in the respective medium (DMEM for astrocytes and MEM for astrocytoma cells) and $2 \mu \mathrm{M}$ ${ }^{3}[\mathrm{H}]$ myo-inositol was added). Incubation was performed at $37^{\circ} \mathrm{C}$ in a humidified atmosphere $\left(5 \% \mathrm{CO}_{2}\right)$. Subsequently, medium was removed and the remaining radioactivity was eliminated by five washing steps with PBS including $40 \mathrm{mM}$ myo-inositol. Lyses was performed with $10 \%$ TCA or $0.1 \mathrm{~N} \mathrm{NaOH}$ for measurement of radioactivity or protein determination, respectively. Radioactive samples were mixed with $3 \mathrm{ml}$ of liquid scintillation fluid (Lumasafe; Canberra-Packard, 
Groningen, The Netherlands) and counted. Determinations were done in triplicate.

For determination of the time course of the drug effects, cells were cultivated for 16 days (astrocytoma cells) or four weeks (cultured astrocytes) before the uptake of ${ }^{3}[\mathrm{H}]$-myo-inositol was determined (six hours incubation time). One to 15 days before that time the various drugs were added and medium was changed twice weekly.

\section{Protein Determination}

Total cell protein was measured according to Bradford (Bradford 1976) using the Bio-Rad Protein Assay (BioRad Laboratories, Munich, Germany) and bovine serum albumin (Sigma, Deisenhofen, Germany) as standard. Determinations were done in duplicate.

\section{mRNA Extraction}

Cells were lysed in guanidinium isothiocyanate/mercaptoethanol (GTC) solution (500 $\mu \mathrm{l} /$ well). Total RNA was extracted according to Chomczynski and Sacchi (1987).

\section{Reverse Transcription}

One microgram of total RNA was transcribed into cDNA in a total volume of $25 \mu \mathrm{l}$ containing $0.5 \mu \mathrm{l}$ M-MLV RT (Gibco), $0.5 \mu$ l RNA'se inhibitor (Pharma-

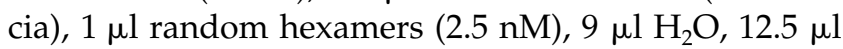
10x buffer (Pharmacia), $4 \mu \mathrm{l}$ DTT $(0.1 \mathrm{M})$, and $5 \mu \mathrm{l}$ dNTP's (2.5 mM). After $10 \mathrm{~min}$ of incubation at $30^{\circ} \mathrm{C}$ and $60 \mathrm{~min}$ at $42^{\circ} \mathrm{C}$, the reaction was stopped by heating at $95^{\circ} \mathrm{C}$ for $5 \mathrm{~min}$. Potential contamination by genomic DNA was checked by omitting reverse transcriptase and using S12 primers in the subsequent PCR amplification. Only RNA samples showing no bands after this procedure were used for further investigations.

\section{Polymerase Chain Reaction (PCR)}

One microliter of the RT-reaction was used for PCR amplifications. The following reagents were added: $4 \mu \mathrm{l}$ $\mathrm{MgCl}_{2}$, $(25 \mathrm{mM}), 5 \mu \mathrm{l}$ 10x PCR Buffer (Pharmacia), $4 \mu \mathrm{l}$ dNTPs $(10 \mathrm{mM}), 35 \mu \mathrm{H} \mathrm{H}_{2} \mathrm{O}, 0.5 \mu \mathrm{l}$ of each primer, and $0.125 \mu \mathrm{l}$ Taq Polymerase (Pharmacia). PCR conditions were as follows: $1 \mathrm{~min}$ denaturation at $94^{\circ} \mathrm{C}, 1 \mathrm{~min}$ primer annealing and $1.5 \mathrm{~min}$ amplification at $72^{\circ} \mathrm{C}$. PCR was terminated after an incubation at $72^{\circ} \mathrm{C}$ for 7 min. Sequences of oligonucleotide primer pairs and PCR conditions were as follows: rat SMIT primers used for semiquantitative RT-PCR \# 207 (5'-AGGGACTGGAGCTGCAAGTGG) and \# 1154 (5'-CTGTTGAAGATGGAGGCCA); annealing temperature, $58^{\circ} \mathrm{C}, 32$ cycles. S12 ribosomal protein (Ayane et al. 1989) \# 49 (5'-ACGTCAACACTGCTCTACA) and \# 360 (5'-CTT-
TGCCATAGTCCTTAAC); annealing temperature $56^{\circ} \mathrm{C}$, 28 cycles. The plateau phase of the PCR-reaction was not reached under these conditions.

\section{Quantification of PCR-Products}

Amplified cDNAs were separated by agarose gel electrophoresis and analyzed using the One-DeScan gel imaging system (MWG Biotech, Munich). Arbitrary units of SMIT mRNA were correlated to arbitrary units S12 mRNA $(=100 \%)$ of the same sample. Results are given as means \pm SD from four RNA samples, obtained from four independent cell preparations with four independent RNA extractions.

\section{RESULTS}

Time Course of the Effects of Antibipolar Drugs and Amitriptyline on High Affinity Myo-Inositol Uptake in Cultured Primary Astrocyte

The effects of chronic pretreatment with antibipolar drugs on the high affinity myo-inositol uptake were studied in the human astrocytoma cell line U373 MG and in primary astrocyte cultures from rat brain. The uptake of ${ }^{3}[\mathrm{H}]$-inositol in both astrocytes (Figure 1) and astrocytoma cells (not shown) is linear up to approximately $6 \mathrm{hrs}$; a steady state is reached after $24 \mathrm{hrs}$.

We have verified the high affinity nature of this uptake by assessment of its $\mathrm{Km}(50 \mu \mathrm{M}$ in cultures from cortex and tegmentum, $27 \mu \mathrm{M}$ in cultures from other areas) (Lu-

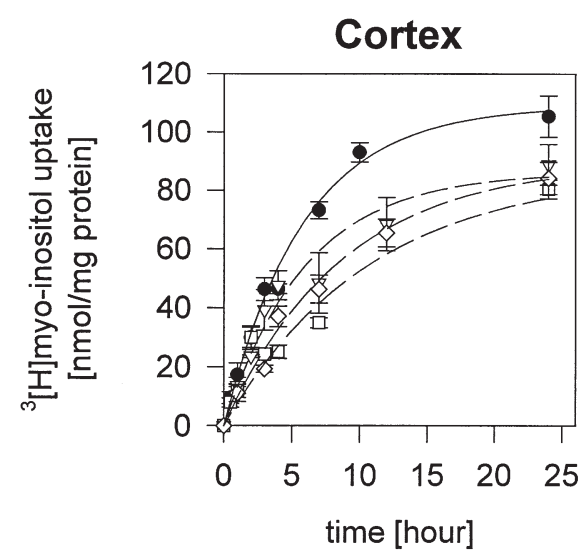

Figure 1. Time course of ${ }^{3}[\mathrm{H}]$ myo-inositol uptake in primary astrocyte cultures of cortex. Individual cultures were incubated as described in the "Methods" section for the indicated time periods after 14-day preincubation with vehicle $(\bullet), 1 \mathrm{mM}$ lithium $(\square), 50 \mu \mathrm{M}$ carbamazepine $(\nabla)$, or $0.6 \mathrm{mM}$ valproate $(\diamond)$. Results are means \pm S.D. (Student's $t$-test). Similar results were obtained for the kinetics of uptake also in astrocyte cultures from the other brain regions and the astrocytoma cell line U373 MG, whereas the extent of uptake and of the inhibition by antibipolar drugs varied as evident from Figure 4. 

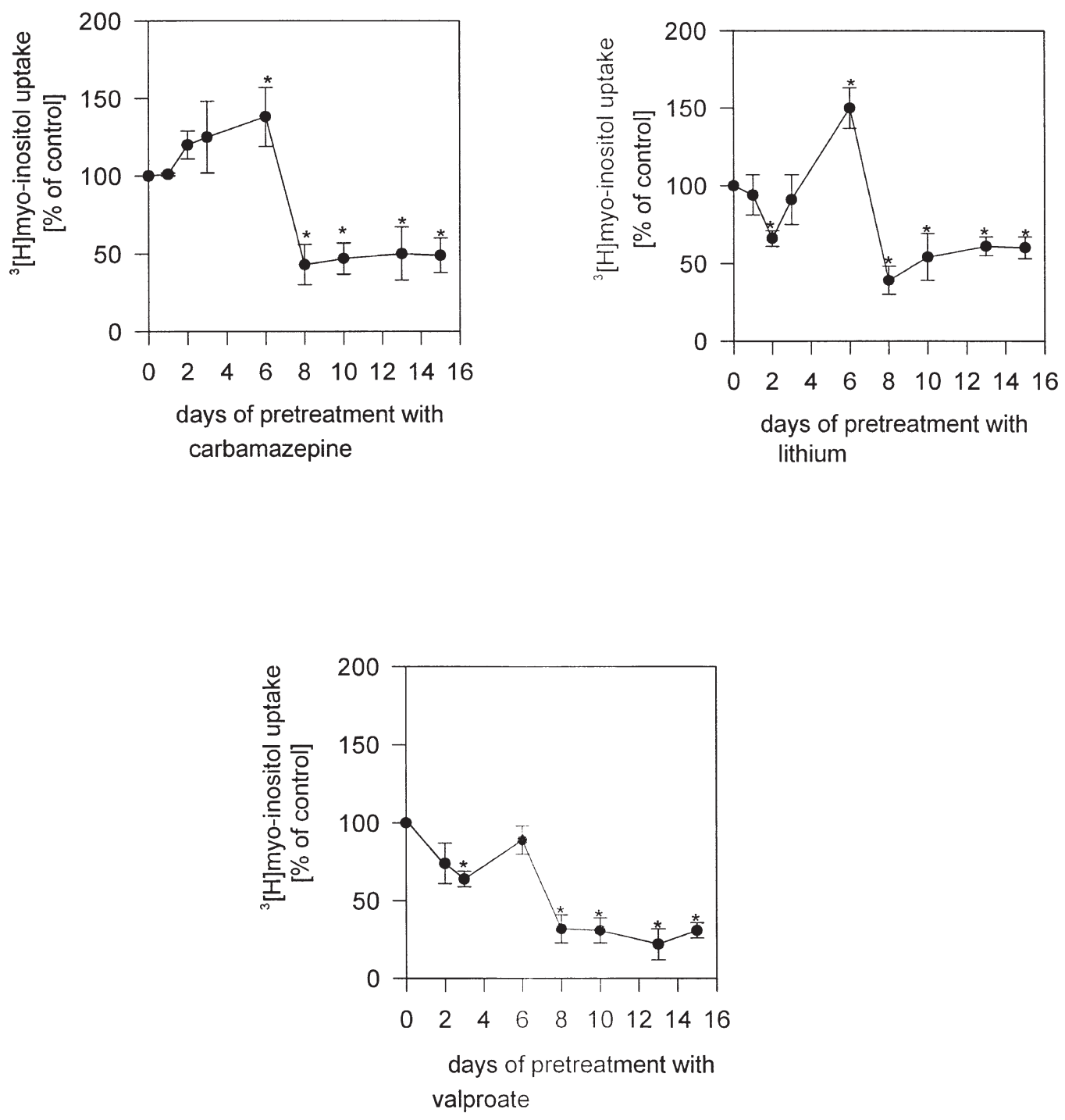

Figure 2. ${ }^{3}[\mathrm{H}]$ myo-inositol uptake in U373 MG human astrocytoma cell line after pretreatment with carbamazepine (50 $\mu \mathrm{M})$, lithium chloride $(1 \mathrm{mM})$, or valproate $(0.6 \mathrm{mM})$, respectively. Cells were seeded and cultivated for 16 days. Antibipolar drugs were added 1-15 days before the uptake was assessed by incubation with ${ }^{3}[\mathrm{H}] \mathrm{myo}$-inositol for six hours as described in "Methods." Control cultures were pretreated for the identical times but received vehicle only. Values are given as means of four experiments \pm S.D. ${ }^{*} p<.01$ (Wilcoxon test) compared to controls $(9.7 \pm 0.2 \mathrm{nmol} / \mathrm{mg}$ protein).

brich et al. submitted) and its inhibition by L-fucose (our unpublished results). Chronic (14 d) treatment with lithium, carbamazepine, and valproate inhibits the uptake in astrocytes (Figure 1) and astrocytoma cells (not shown). The uptake kinetics and its alteration by the three antibipolar drugs are illustrated for astrocytes from cortex in Figure 1. The time course of the effects of the antibipolar drugs in U373 MG cells (Figure 2) and astrocytes (Figure 3) was assessed by measuring the uptake during six hours, i.e., within the linear range of uptake (Figure 1). In astrocytoma cells, lithium and carbamazepine initially provoke an increase of uptake capacity with a maximum after six days of pretreatment, which is, in the case of lithium, preceded by a small decrease of inositol uptake on the second day of pretreatment. The increase is followed by the development of an inhibition of uptake which is evident after eight days of pretreatment and persists up to at least 15 days. Similarly to lithium, also valproate causes an initial decrease of uptake, which is followed first by an increase or shoulder in the time course and then by a further inhibition, which also persists up to at least day 15 .

Preincubation with lithium, carbamazepine, and valproate induces also an inhibition of uptake in cultured astrocytes. The time course of these effects was studied in cultures of cells from cortex (Figure 3). In contrast to the results obtained in astrocytoma cells, primary astrocyte cultures showed no activation of inositol uptake during the first six days of pretreatment but a rather gradually 

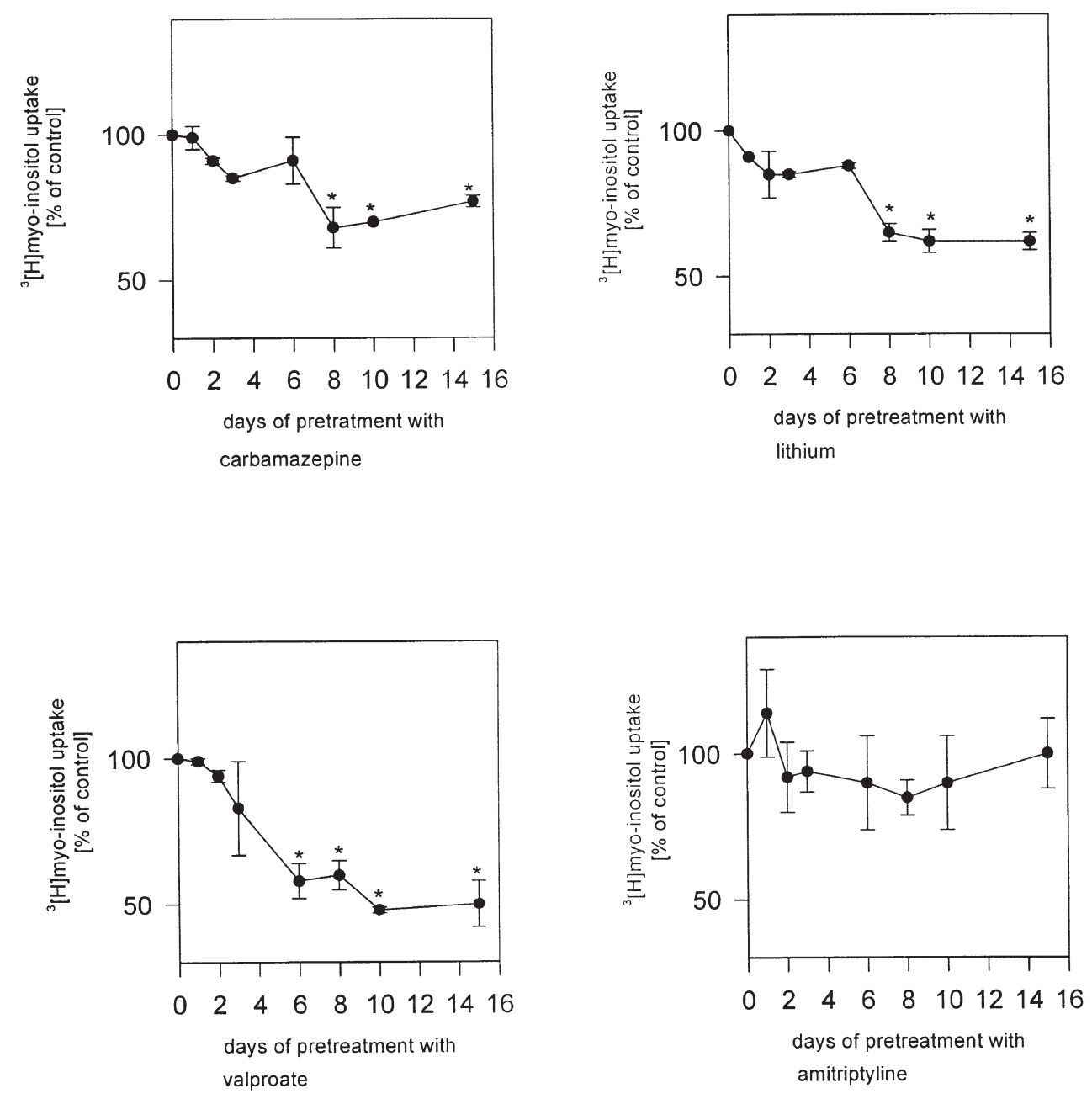

Figure 3. ${ }^{3}[\mathrm{H}]$ myo-inositol uptake in primary astrocyte cultures of rat cortex after pretreatment with $50 \mu \mathrm{M}$ carbamazepine, $1 \mathrm{mM}$ lithium chloride, $0.6 \mathrm{mM}$ valproate, or $0.5 \mu \mathrm{M}$ amitriptyline. Cells were cultivated for four weeks. The various drugs were added 1-15 days before the end of this total cultivation time. Control cultures were pretreated for the identical times but received vehicle only. After pretreatment cultures were washed and incubated for six hours with ${ }^{3}[\mathrm{H}]$ myo-inositol for determination of uptake capacity as described in "Methods." Values are given as means of four experiments \pm S.D. ${ }^{*} p<.01$ (Wilcoxon test) compared to controls $(48.4 \pm 2.8 \mathrm{nmol} / \mathrm{mg}$ protein).

developing inhibition that reached its maximum after about one week and persisted thereafter up to at least 15 days. However, also in astrocytes the time course showed a shoulder at the time, where an activation of uptake was observed in astrocytoma cells (Figure 3).

In contrast to the effects of the antibipolar drugs, the tricyclic antidepressant amitriptyline at a concentration equivalent to the plasma level used clinically $(0.5 \mu \mathrm{M})$ did not influence significantly the myo-inositol uptake capacity of primary astrocyte cultures (Figure 3).

\section{Effects of Antibipolar Drugs on Cultured Primary Astrocytes from Different Brain Regions}

Chronic pretreatment (14 days) with antibipolar drugs inhibited the uptake rate of ${ }^{3}[\mathrm{H}]$ myo-inositol in primary astrocyte cultures of cells from all brain regions examined, with the exception of cultures of cells from diencephalon where only carbamazepine and valproate, but not lithium, were effective (examplified for astrocytes from cortex in Figure 1). This reduction was also evident at the steady-state levels (24 hrs incubation with ${ }^{3}[\mathrm{H}]$ myo-inositol) and was most pronounced in cultures of cells from cerebellum and tegmentum (Figure 4). In contrast, in cultures of cells from cortex and hippocampus the reduction of steady-state levels was much less pronounced and significant only for pretreatment with either lithium or valproate, but not with carbamazepine. Primary astrocyte cultures of diencephalon are unique in exhibiting a pronounced inhibition of uptake after pretreatment with carbamazepine and valproate but no effect of lithium (Figure 4). 

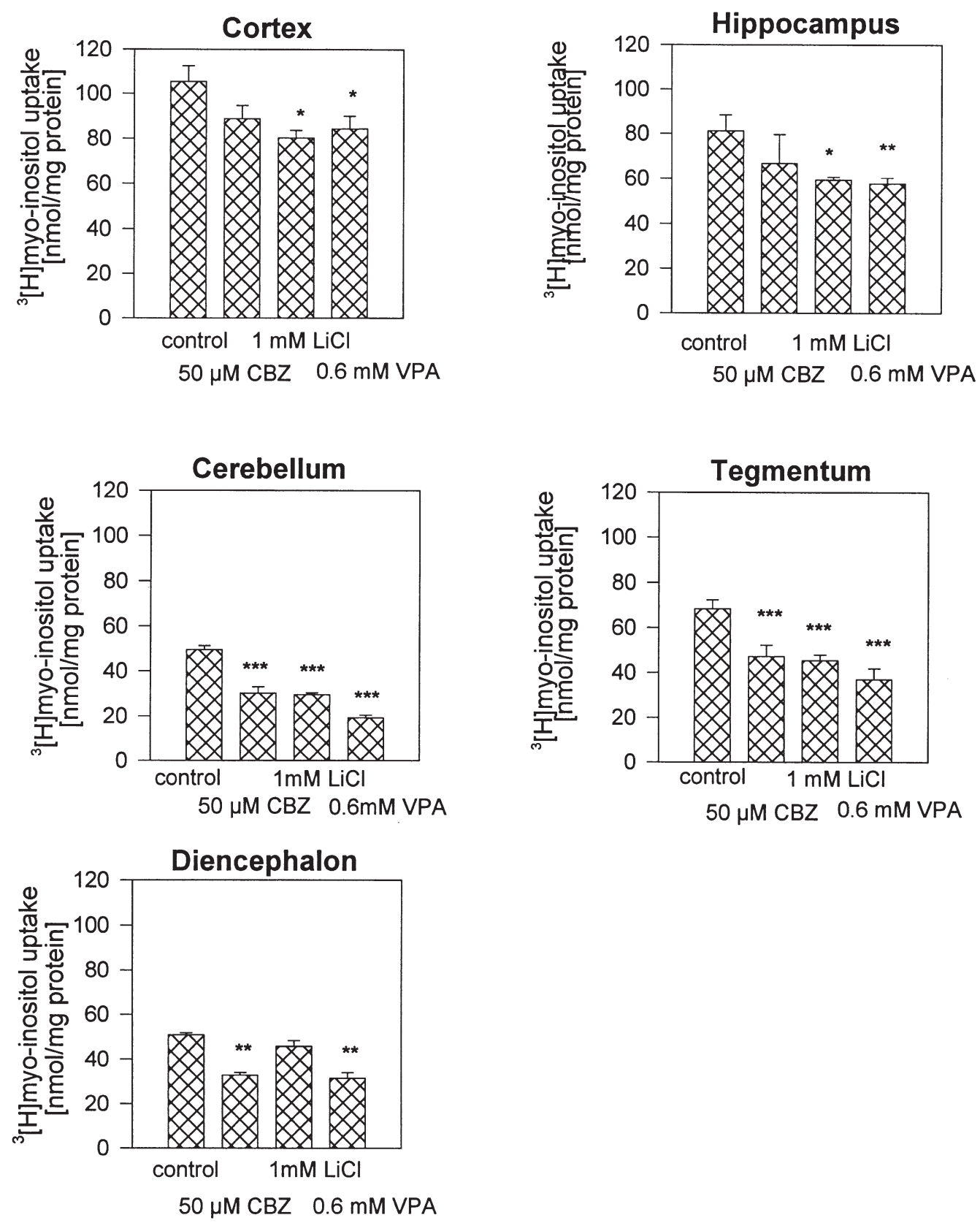

Figure 4. Changes in steady-state levels of ${ }^{3}[\mathrm{H}]$ myo-inositol (24 hrs of incubation) in astrocyte cultures after chronic treatment with lithium $(\mathrm{LiCl}, 1 \mathrm{mM})$, carbamazepine $(\mathrm{CBZ}, 50 \mu \mathrm{M})$, or valproate $(\mathrm{VPA}, 0.6 \mathrm{mM})$. Control (co) levels were $49.5 \pm 1.8$ $\mathrm{nmol} / \mathrm{mg}$ protein for cerebellum, $83.1 \pm 0.67 \mathrm{nmol} / \mathrm{mg}$ protein for cortex, $50.9 \pm 1.6 \mathrm{nmol} / \mathrm{mg}$ protein for diencephalon, $81.3 \pm 0.87 \mathrm{nmol} / \mathrm{mg}$ protein for hippocampus, and $68.4 \pm 0.56 \mathrm{nmol} / \mathrm{mg}$ protein for tegmentum. Values are given as means of six experiments \pm S.D. ${ }^{*} p<.005 ;{ }^{* *} p<.001 ;{ }^{* * *} p<.0001$ (Student's $t$-test) compared to controls.

\section{Effects of Antibipolar Drugs on the Content of SMIT mRNA in Primary Astrocyte Cultures}

Semiquantitative determination of SMIT mRNA content was performed in primary astrocyte cultures of cells from cortex and cerebellum as examples of cultures with high and low basal activity of the high affinity myo-inositol uptake, respectively. This corresponds with high and low content of SMIT mRNA in cultures from these areas, respectively (Lubrich et al. submitted). Chronic (14 days) pretreatment with carbamaz- epine, lithium, or valproate resulted in statistically significant decreases of mRNA content in cultures of cells from both regions (Figure 5).

\section{DISCUSSION}

The results of the present study provide evidence that all three drugs known to exhibit clinically proven antibipolar efficacy in patients, share at therapeutically rel- 
A:

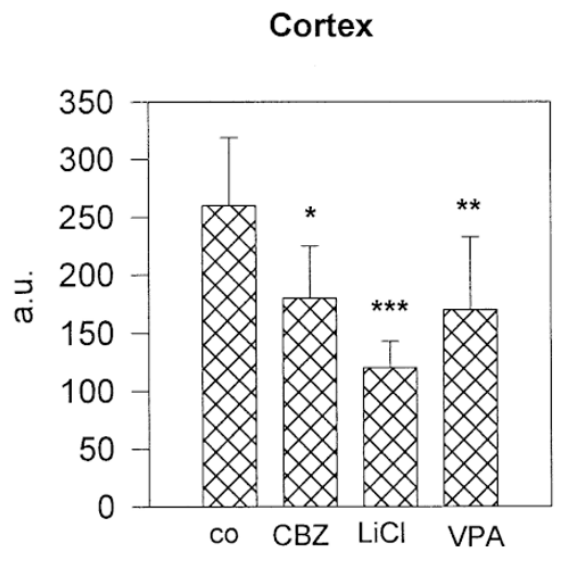

B:

SMIT (947 bp)

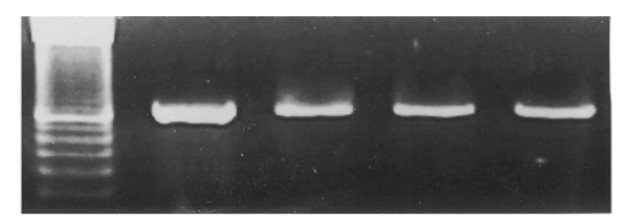

$\mathrm{S} 12(311 \mathrm{bp})$

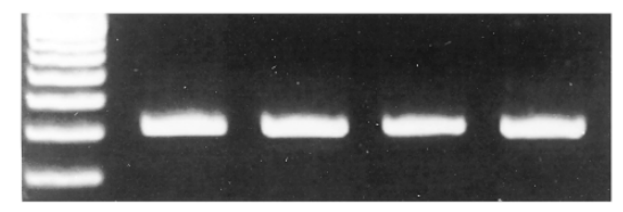

$\begin{array}{llll}1 & 2 & 3 & 4\end{array}$
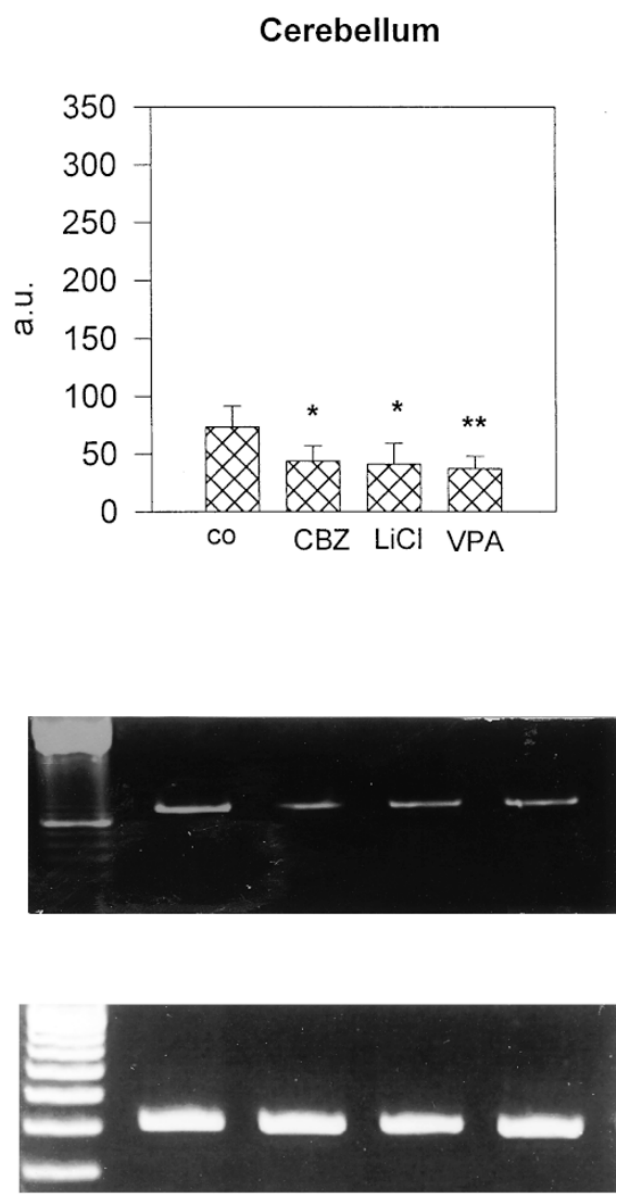

12

Figure 5. Semi-quantitative determination of SMIT mRNA content in primary astrocytes cultured from cerebellum and cortex after chronic pretreatment (14 days) with carbamazepine (CBZ), lithium ( $\mathrm{LiCl}$ ), and valproate (VPA) compared to controls (co). Total RNA was reverse transcribed and transporter cDNAs were quantified using ribosomal protein S12 cDNA as internal standard (for details see "Methods"). (A) SMIT cDNA quantified by a gel analytic program. Arbitrary units of SMIT cDNA were normalized to S12 cDNA (=1). Values are given as means of four experiments \pm S.D. ${ }^{*} p<.005$; ${ }^{* *} p<.001 ;{ }^{* * *} p<.0001$ (Student's $t$-test, one tailed). (B) RT-PCR products using SMIT primers (upper panel) or primer for S12 (lower panel). RNA was prepared from primary astrocyte cultures derived from cerebellum and cortex. The bright band in marker lanes is $800 \mathrm{bp}$. Lane 1: controls; Lane 2: pretreatment with carbamazepine; Lane 3: pretreatment with lithium; Lane 4: pretreatment with valproate.

evant concentrations and with a time course similar to the onset of their clinical effects, one biochemical property, the inhibition of activity of the high affinity myoinositol uptake in astrocytes (both of human and rat origin) together with a concomitant decrease in the content of the respective mRNA. These results appear particularly relevant, since the "inositol depletion hypothesis," the presently prevailing hypothesis of lithium's action, postulates a depletion of inositol in overactivated neural circuits as the principal initial event in the mechanism of action of lithium ions (Berridge et al. 1989). While this hypothesis originally explained lith- ium's inositol depleting effect by uncompetitive inhibition of IMPase, our results suggest that inhibition of the high affinity myo-inositol uptake could reinforce this action of lithium and might, in addition, also mediate the effects of valproate and carbamazepine. It is of historical interest that an effect of lithium on inositol transport has already been proposed in the very first publication about lithium's effect on brain inositol (Allison and Steward 1971).

A potential alternative explanation for the data of the present report could be that chronic treatment with mood stabilizers activates an outward transport of ino- 
sitol, which would result in a release of unlabelled inositol during incubation and a consequent reduction of the specific activity of ${ }^{3}[\mathrm{H}]$-myo-inositol that could be misconceived as inhibition of uptake. We have, however, shown (Figure 5) that not only the uptake of ${ }^{3}[\mathrm{H}]-$ myo-inositol, but also the level of SMIT mRNA, is downregulated by chronic treatment with mood stabilizers, which suggests that the high affinity transport is altered by these stabilizers. Whether or not, in addition, the efflux of inositol might be modified by antibipolar drugs cannot be assessed by the present experiments and must be clarified in subsequent studies.

Effects of antibipolar drugs on myo-inositol transport have not been reported previously with one notable exception: Very recently Wolfson et al. (1998) in their study of cultured mouse astrocytes have observed a reduction of steady state levels ("pool size") of myoinositol after one to eight days of preincubation with lithium. While this finding is in agreement with the results presented here, these authors did not find an inhibition of uptake rates after eight days of lithium treatment, in direct contradiction to the results of our study. However, since these authors investigated apparently only cultures treated for up to eight days, they may well have overlooked effects occurring later. Already, a small shift to the right of the time course of the lithium induced effects and/or a more pronounced initial, transitory increase of uptake or shoulder in the time course (see Figures 2 and 3) could have caused their measurement to be made at a time point, where the inhibition, if any, is only marginally pronounced. Such subtle alterations in the time course could be readily explained by the differences between their mouse astrocytes that were treated with dibutyryl cyclic AMP and the rat cultures used in our study, which were free of dibutyryl cyclic AMP.

PKC isoenzymes have received particular attention as potential targets in the mechanism of action of lithium and other antibipolar drugs (Manji and Lenox 1994; Manji et al. 1995, 1996; Lenox et al. 1996). Since PKC is known to acutely inhibit the activity of the high affinity inositol transporter (Handler and Kwon 1993; Batty et al. 1993), it is tempting to speculate that modifications of PKC activity might also be responsible for the effects of antibipolar drugs on this system. The effects of lithium ions on the activity of PKC can be divided into several phases (for review see Manji and Lenox 1994): Initially lithium ions appear to increase PKC activity. More chronic treatment leads via proteolytic degradation to "downregulation" of membrane-bound PKC activity, which may be associated with increased nuclear PKC activity that could modify gene expression. This sequence of events might partially explain the peculiar time course of lithium's effects on the activity of the high affinity inositol uptake system in astrocytoma cells, which shows three distinct phases (Figure
2). In agreement with an initial increase of PKC activity inositol uptake is first transiently inhibited. This is followed by an increase of uptake capacity, which could be interpreted as the result of subsequent downregulation of PKC. Subsequently, persistent inhibition of uptake develops. This third phase is probably due to concomitant or subsequent inhibition of gene expression of the myo-inositol transporter, since the level of SMIT mRNA was found to be reduced after 14 days of lithium treatment (Figure 4). In agreement with a role of PKC, we have obtained preliminary evidence that the peculiar time course of lithium in the modulation of inositol uptake can be mimicked by the application of specific activators and inhibitors of PKC isoenzymes (Lubrich and van Calker, unpublished).

Various other mechanisms must be considered. Thus, lithium induces an activation of the transcription factors c-fos and c-jun (Manji and Lenox 1994), which may cause a rapid increase of the expression of SMIT (Cohen et al. 1991) and may contribute to the increase of inositol uptake observed in the second phase (Figure 2). In addition, the activity of SMIT protein is also regulated by protein kinase A (Preston et al. 1995) and thus also dependent on the cyclic AMP pathway. Since lithium ions both acutely and chronically influence the activity and gene expression, respectively, of adenylate cyclase (for review see Mork et al. 1992; Manji et al. 1995), effects elicited via modifications of cyclic AMP accumulation could also play a significant role.

Interestingly, the three phases in the time course of lithium's effect on inositol uptake are particularly pronounced only in astrocytoma cells, whereas, in primary astrocytes the second phase (activation of uptake) only shows as a shoulder in the time course (Figure 3). This could be explained by, e.g., a different timing and ratio of the various mechanisms described above in primary astrocytes as compared to their transformed counterparts. Indeed, tumor cells often show a more pronounced PKC activation (McCarthy 1996; Baltuch et al. 1995; Couldwell et al. 1992).

Valproate appears to share with lithium ions the property to modify the activity of several isoenzymes of PKC (Manji et al. 1996; Chen et al. 1994), albeit apparently acting via different mechanisms (Lenox et al. 1996). Accordingly, the time course of the effects of valproate on inositol uptake in astrocytoma cells is strikingly similar to that of lithium ions (Figure 2), although the second phase (activation of uptake) only shows as a shoulder in valproate treated cells (Figure 2).

Unlike the effects of lithium and valproate, chronic treatment with carbamazepine does not seem to influence PKC activity (Lenox et al. 1996). Furthermore, earlier attempts to identify carbamazepine-induced alterations of phosphoinositol signaling have lead to equivocal results (McDermott and Logan 1989; Elphick et al. 1988). It may, therefore, be surprising that carba- 
mazepine evokes effects on inositol uptake, which follow a time course somewhat similar to that of the actions of lithium and valproate, with the exception of the initial decrease in activity in astrocytoma cells, which is not observed with carbamazepine (Figure 2). However, several of the potential mechanisms discussed above could also apply for carbamazepine's action. Particularly, carbamazepine has been shown to inhibit both basal and stimulated cyclic AMP accumulation (Chen et al. 1996; van Calker et al. 1991) and may, thus, influence the inositol transporter, e.g., via direct effects mediated by protein kinase A and indirectly via modulation of c-fos induction (Manji et al. 1996; Divish et al. 1991) and subsequent alterations of SMIT gene transcription (Cohen et al. 1991).

The inhibition by antibipolar drugs of the myo-inositol transporter appears to be a specific effect of this class of substances, since at least the tricyclic antidepressant amitriptyline did not evoke similar effects in primary astrocytes. Thus, inhibition of myo-inositol transport might be related to the mood stabilizing effect of these compounds, while tricyclic antidepressants are generally not beneficial as mood stabilizers in bipolar disorder but may even provoke manic or mixed episodes and cycle acceleration (Altshuler et al. 1995).

The decrease in the level of SMIT mRNA observed in astrocytes from cerebellum (approximately $40 \%$; see Figure 5) is roughly comparable to the inhibition of uptake as evident from the steady state levels (40-60\%), whereas in astrocyte cultures from cortex, this decrease of mRNA appears to be more pronounced ( $30 \%$ for CBZ and VPA, 50\% for lithium) than the inhibition of uptake (approximately 20\%). It must, however, be stressed that determination of mRNA by the RT-PCR method applied does not allow any quantitative statements as to the real amount of mRNA present but is at best a semiquantitative measure of the relative alterations induced.

The extent of inhibition evoked by the three drugs is not uniform but distinct in primary astrocytes cultured from different brain regions (Figure 4). This is particularly evident from the steady state levels that are obtained after $24 \mathrm{hrs}$ of incubation with ${ }^{3}[\mathrm{H}]$ myo-inositol (Figure 4). The reason for these differences are unclear. However, a differential impact of the various potential mechanisms discussed above depending on the type of astrocytes could be envisaged. These results add to the growing body of evidence that cultured primary astrocytes from different brain regions differ in their biochemical properties (Lee et al. 1994; Shao et al. 1994; Hansson 1990) the notion that they also may respond differentially to pharmacological treatments.

In contrast to historical views that had attributed to glial cells only a passive role as "neuro-glue" ("Nervenkitt") astrocytes are now appreciated as actively contributing to neural function, e.g., through interglial and reciprocal glia/neuron communication by way of cal- cium waves (for recent reviews see Dermietzel and Spray 1998; Verkhratsky et al. 1998). Astrocytes appear to be particularly important for the myo-inositol homeostasis in the brain since they accumulate inositol more intensely (Glanville et al. 1989) and express much higher amounts of SMIT mRNA than neurons (our unpublished results). Thus, while the original inositol depletion hypothesis has only implied neurons as the target of lithiums dampening effect on phosphoinositol signaling, there is no inherent reason to restrict this action to neuronal cells, since also glial cells express this signal transduction system (Verkhratsky et al. 1998) and are actively involved in information processing.

A particularly compelling feature of the original "inositol depletion" hypothesis was that it offered an explanation for the hitherto unexplained property of lithium to specifically influence only the altered mood of individuals with affective disorders, leaving almost unaltered the psychological functioning of normal subjects. This was hypothesized to be due to lithium's uncompetitive mode of inhibition of IMPase, which would result in an inhibition that is the more pronounced the more the phosphoinositol signaling is activated. Relevant inhibition and, thus, inositol depletion and its sequelae would therefore be restricted to pathologically overactivated pathways. In agreement with this postulate, we have found that chronic treatment with lithium reduces the level of inositol only in the hypothalamus, perhaps because this region is particularly activated due to the stress of chronic lithium feeding (Lubrich et al. 1997). Inositol depletion evoked by inhibition of high affinity inositol uptake is, in contrast, observed in astrocyte cultures of several brain regions and may, therefore, be less selective in its impact on signal transduction. One potential explanation for this discrepant findings might be that cultured astroglia in vitro, although they share several properties with their counterparts in vivo (Duffy and MacVicar 1995), are nevertheless heavily proliferating and particularly activated, at least in part due to the absence of the inhibitory influence of neurons (for review see McMillan et al. 1994). Thus, the sensitivity to inhibition by mood stabilizers of the inositol uptake in these cultures may reflect the properties of activated astrocytes, whereas, resting astrocytes in vivo might be much less prone to these effects. Furthermore, even with significant downregulation of SMIT mRNA and myo-inositol uptake rates, the steady-state levels of myo-inositol in primary astrocyte cultures are reduced only to $50 \%$ at most, and resting astrocytes in vivo might maintain even higher levels of inositol (see above). This concentration might well be sufficient to replenish intracellular inositol for phosphoinositide resynthesis during normal activation and function. However, in states of pathological overactivation, PKC activity could increase to a degree that further downregulate inositol uptake up to an extent that 
does not fulfill the elevated requirements for inositol replenishment. Therefore, treatment with antibipolar drugs would in principle reinforce a physiological feed back mechanism, which would protect the cell against exaggerated stimulation of phosphoinositol signaling. Although presently speculative, such a mechanism might explain why not only lithium, but also the other two mood stabilizers, show a considerable selectivity in their effects on disturbed mood. The ultimate test for the validity of this hypothesis would be the development and analysis of potential clinical efficacy of compounds specifically targeted in their action at inhibition of inositol uptake.

In conclusion, we have provided evidence from in vitro studies that inhibition of the high affinity myoinositol transporter could be relevant in the mechanism of action of antibipolar drugs. The results encourage investigations of the potential clinical usefulness of inositol uptake inhibitors as mood stabilizers that may be advantageous with respect to their risk-benefit profile.

\section{ACKNOWLEDGMENTS}

This work was supported by the German Israel Foundation (Grant No I-245-098.02/92). The authors are indebted to Professor Robert H. Belmaker, Beer Sheva, for continuos encouragement and support.

\section{REFERENCES}

Allison JH, Steward MA (1971): Reduced brain inositol in lithium-treated rats. Nature New Biol. 233:267-268

Altshuler LL, Post RM, Leverich GS, Mikalauskas K, Rosoff A, Ackerman L (1995): Antidepressant-induced mania and cycle acceleration: A controversy revisited. Am J Physiol 152:1130-1138

Ayane M, Nielsen P, Kohler G (1989): Cloning and sequencing of mouse ribosomal S12 cDNA. Nucleic Acids Res $17: 6722$

Baltuch GH, Dooley NP, Rostworowski KM, Villemure JG, Yong VW (1995): Protein kinase C isoform alpha overexpression in C6 glioma cells and its role in cell proliferation. J Neurooncol 24(3):241-250

Batty JH, Michi A, Fennel M, Downes CP (1993): The characteristics, capacity and receptor regulation of inositol uptake in 1321N1 astrocytoma cells. Biochem J 294:49-55

Berridge MJ, Downes CP, Hanley MR (1989): Neural and development actions of lithium: A unifying hypothesis. Cell 59:411-419

Bradford MM (1976): A rapid and sensitive method for the quantitation of microgram quantities of protein utilizing the principle of protein dye binding. Anal Biochem 72:248-254

Chen G, Manji HK, Hawver DB, Wright CB, Potter WZ (1994): Chronic sodium valproate selectively decreases protein kinase $C$ alpha and epsilon in vitro. J Neurochem 63:2361-2364

Chen G, Pan B, Hawver DB, Wright CB, Potter WZ, Manji HK (1996): Attenuation of cyclic AMP production by carbamazepine. J Neurochem 67(5): 2079-2086

Chomczynski P, Sacchi N (1987): Single step method of RNA isolation by acid guanidinium thiocyanat-phenol-chloroform extraction. Anal Biochem 162:156-159

Cohen DM, Wasserman JC, Gullans SR (1991): Immediate early gene and HSP70 expression in hyperosmotic stress in MDCK cells. Am Phys Soc C 261:594-601

Couldwell WT, Antel JP, Yong VW (1992): Protein kinase C activity correlates with the growth rate of malignant gliomas: Part II. Effects of glioma mitogens and modulators of protein kinase C. Neurosurgery 31(4):717-724

Dermietzel R, Spray DC (eds) (1998): Gap Junctions and Glia [Special issue]. GLIA 24:1-150

Divish MM, Sheftel G, Boyle A, Kalasapudi VP, Papolos DF, Lachman HM (1991): Differential effect of lithium on fos protooncogene expression mediated by receptor and postreceptor activators of protein kinase $\mathrm{C}$ and cyclic adenosine monophosphate: Model for its antimanic action. J Neurosci Res 28:40-48

Duffy S, MacVicar BA (1995): Adrenergic calcium signaling in astrocyte networks within the hippocampal slice. J Neurosci 15:5535-5550

Elphick M, Taghavi Z, Powell T, Godfrey PP (1988): Alteration of inositol phospholipid metabolism in rat cortex by lithium but not carbamazepine. Eur J Pharmacol 156:411-414

Gani D, Downes CP, Batty J, Bramham J (1993): Lithium and myo-inositol homeostasis. Biochim Biophys Acta 1177:253-269

Gebicke-Haerter PJ, Bauer J, Schobert A, Northoff H (1989): Lipopolysaccharide-free conditions in primary astrocyte cultures allow growth and isolation of microglial cells. J Neurosci 9:183-194

Glanville NT, Byers HV, Cook MW, spence FB, Palmer C (1989): Differences in the metabolism of inositol and phosphoinositides by cultured cells of neuronal anf glial origin. Biochim Biophys Acta 1004:169-179

Goodwin FK, Jamison KR (1990): Manic-Depressive Illness. New York, Oxford University Press

Hamprecht BH, Löffler F (1985): Primary glial cultures as a model for studying hormone action. Methods Enzymol 109:341-345

Handler SH, Kwon HM (1993): Regulation of renal cell organic osmolyte transport by tonicity. Am Phys Soc 265:1449-1455

Hansson E (1990): Regional heterogenity among astrocytes in the central nervous system. Neurochem Int 16:237-245

Jope RS, Williams MB (1994): Lithium and brain signal transduction systems. Biochem Pharmacol 47:429-441

Lee SH, Kim WT, Cornell-Bell AH, Sontheimer H (1994): Astrocytes exhibit regional specifity in gap-junction coupling. GLIA 11:315-325

Lenox RH, McNamara RK, Watterson JM, Watson DG (1996): Myristoylated alanine-rich C kinase substrate (MARCKS): A molecular target for the therapeutic 
action of mood stabilizers in the brain? J Clin Psychiatry 57(suppl 13):23-31

Lubrich B, Kofman O, Agam G, Berger M, Belmaker RH, van Calker D (1997): Lithium-induced inositol depletion in rat brain after chronic treatment is restricted to the hypothalamus. Mol Psychiatry 2:407-412

Manji HK, Lenox RH (1994): Lomg-term action of lithium: A role for transcriptional and posttranscriptional factors regulated by protein kinase $C$. Synapse 16:11-28

Manji HK, Chen G, Hsiao JK, Risby ED, Masana MI, Potter W Z (1996): Regulation of signal transduction pathways by mood stabilizing agents: Implications for the delayed onset of therapeutic efficacy. J Clin Psychiat 57(suppl 13):34-46

Manji HK, Potter WZ, Lenox RA (1995): Signal transduction pathways. Molecular target for lithium's action. Arch Gen Psychiatry 52:531-543

McCarthy MF (1996): Up-regulation of intracellular signalling pathways may play a central role in hypertension; atherogenesis, insulin resistance and cancer promotionthe "PKC syndrome". Med Hypertheses 46(3):191-221

McDermott EE, Logan SD (1989): Inhibition of agonist-stimulated inositol lipid metabolism by the anticonvulsant carbamazepine in rat hippocampus. Br J Pharmacol 98:581-589

McMillan MK, Thai L, Hong J-S, O'Callaghan JP, Pennypacker KR (1994): Brain injury in a dish: A model for reactive gliosis. Trends NeuroSci 17:138-142
Mork A, Geisler A, Hollund P (1992): Effects of lithium on second messenger systems in brain. Pharmacol Toxicol 71:4-17

Patishi Y, Lubrich B, Berger M, van Calker D, Belmaker RH (1996): Differential uptake of myo-inositol in vivo into rat brain areas. Eur Neuropsychopharmacol 6:73-75

Preston AS, Yamauchi A, Kwon HM, Hander JS (1995): Activators of protein kinase $A$ and of protein kinase $C$ inhibit MDCK cell myo-inositol and betaine uptake. J Am Soc Nephrol 6:1559-1564

Shao Y, Porter JT, McCarthy KD (1994): Neuroligand receptor heterogenity among astroglia. Perspect Dev Neurobiol 2:205-215

van Calker D, Steber R, Klotz KN, Greil W (1991): Carbamazepine distinguishes between adenosine receptors that mediate different second messenger responses. Eur J Pharmacol 206:285-290

Verkhratsky A, Orkand RK, Kettenmann H (1998): Glial calcium: Homeostasis and signaling function. Physiol Rev 78:99-141

Wiesinger H (1991): Myo-inositol transport in mouse astroglia-rich primary cultures. J Neurochem 56:1698-1704

Wolfson M, Hertz E, Belmaker RH, Hertz L (1998): Chronic treatment with lithium and pretreatment with excess inositol reduce inositol pool size in glia like cells by different mechanisms. Brain Res 787:34-40 